\title{
Immunodepression and Immunosuppression During Aging
}

\author{
Véronique Thomas-Vaslin, Adrien Six, Hang-Phuong Pham, \\ Cira Dansokho, Wahiba Chaara, Bruno Gouritin, \\ Bertrand Bellier and David Klatzmann \\ UPMC Univ Paris 06, UMR7211, Immunology, Immunopathology, \\ Immunotherapy, Paris \\ CNRS UMR7211, Integrative Immunology: Differentiation, Diversity, Dynamics, Paris
}

France

\section{Introduction}

Much work has been done to understand isolated aspects of the immune system and effects of immunosuppression in young adults. However there has been little attempt to understand changes throughout the entire life-span of an organism, across organs, genetic backgrounds and at various scales of biological detail and to assess the effects of immunosuppression in old individuals.

The immune system plays a central role in a number of physiological phenomena to maintain the integrity of the individual, by a complex dynamic equilibrium involving immunity and inflammation, but also tolerance, in particular during the gestation. Disequilibrium can lead to pathological disorders such as auto-immune and infectious diseases, cancers and so on. With aging, there is a progressive alteration of the immune system and its responses, resulting in immuno senescence and immunodepression. Of importance thymic involution and infection contribute to aging of the immune system (Gress and Deeks 2009). This leads to less efficient lymphocyte production, activation and responsiveness, increased susceptibility to inflammatory responses and autoimmunity and decreased responses to infections, tumours and vaccinations, see reviews (2005; 2009; Aspinall and Goronzy 2010).

The most important feature of the immune system is to be able to respond to an almost infinite number of antigens and perform immune function to maintain the integrity of the individual. This activity depends on the availability of a diverse repertoire of lymphocytes, i.e. a collection of lymphocytes, each characterized by its antigen-specific receptor produced by random somatic rearrangements of $\mathrm{V}(\mathrm{D}) \mathrm{J}$ gene segments during lymphocyte differentiation. The selection constraints are important in particular for the initial construction of the immune system (in foetus/newborn), or for reconstitution in immunodeficient recipients (Ciupe, Devlin et al. 2009), but also during attrition with aging. In this line, recent studies regarding the question of lymphocyte diversity, selection and available niches have been discussed (Stirk, Molina-Paris et al. 2008; Ciupe, Devlin et al. 2009; Leitao, Freitas et al. 2009). Moreover, in old individual mice or humans, clonal 
expansions are often observed in CD8 T cells, probably as a result of chronic and repeated infections. This reduces the diversity of the repertoire (Ahmed, Lanzer et al. 2009), decreases the potential to drive an immune response and affects the CD4/CD8 ratio (LeMaoult, Messaoudi et al. 2000; Messaoudi, Lemaoult et al. 2004 ; Clambey, van Dyk et al. 2005; Goronzy and Weyand 2005; Pawelec, Akbar et al. 2005; Clambey, Kappler et al. 2007) reviewed in (Blackman and Woodland 2011). With age CD4 T cells have increased longevity (Tsukamoto, Clise-Dwyer et al. 2009) while under normal homeostatic conditions recent thymic migrant have to compete with already established mature naïve T cells (Houston, Higdon et al. 2011).

On the life-scale, lymphocyte and lymphoid organ emergence, cell selection and expansion during ontogeny are critical features of the immune system construction and determine its efficiency at the adult age. Thus, during life, homeostasis is maintained with a dynamic equilibrium between diversity and efficiency (naïf vs. effector/memory lymphocytes) with two periods of physiological relative immunodeficiency, early in ontogeny and in advanced old age. In females, the gestation also represents a relative immunodepressive period leading to embryo/foetus acceptance. During the life, dynamic equilibrium ensures complex interactions of highly diversified circulating lymphocytes, with high turnover, responsible for tolerance and immune protection of the organism, while controlling most pathogens. Aging however induces complex and progressive alterations that find their origins at different biological scales: organism, organ, cell populations, cells, molecules, genes. Table 1 summarizes some of these general observations.

\section{Immune systems aging: multilevel scales}
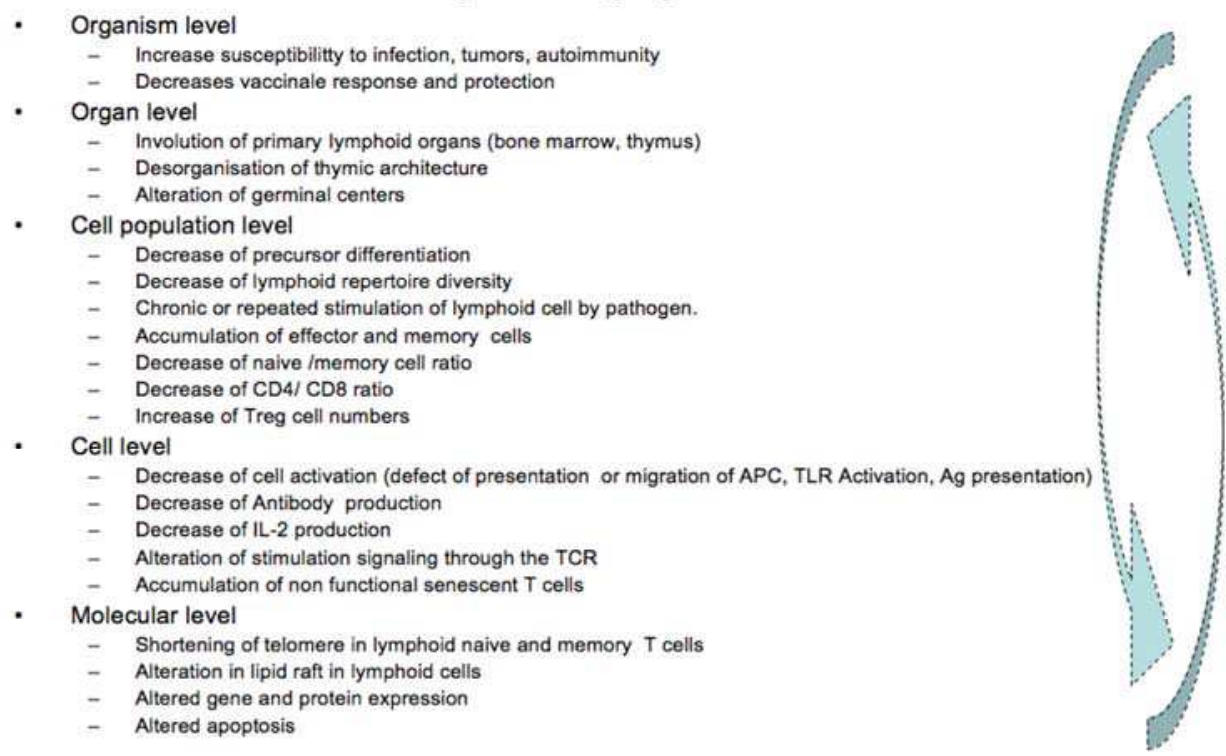

Table 1. Aging alters immune functions at various biological levels. The levels can interfere with each other as depicted by the arrows. 
Thymic involution is a primary sign of immunological aging at puberty and the reduced production of diverse naïve $\mathrm{T}$ cells is compensated for in the immune system by the proliferation of existing peripheral $\mathrm{T}$ cells. In very old humans and mice this leads to alteration in the $\mathrm{T}$ cell repertoire, appearance of oligoclonal expansions, restricting the lymphocyte repertoire (Messaoudi, Lemaoult et al. 2004; Clambey, van Dyk et al. 2005). Thymic involution is likely the result of alterations at different levels, aging being related to alteration of molecular process as somatic recombination of V-D-J gene, that seems related to deficiency in the RAG enzyme, leading to diminution of thymic export (Hale, Boursalian et al. 2006), and recent thymic emigrants (Boursalian, Golob et al. 2004). Direct alterations of thymocyte proliferation, differentiation process or environmental factors as alteration of the thymic epithelium also impact thymocyte differentiation (Thoman 1995; Yehuda, Friedman et al. 1998; Andrew and Aspinall 2001). In elderly humans, altered homeostasis also participates to decrease ratio of naive/memory and CD4/CD8 cells, with senescence of CD4 T cells (Ferrando-Martinez, Ruiz-Mateos et al.).

Moreover, genetic \& epigenetic mechanisms (Yung and Julius 2008) participate to control or trigger aging alterations (Dorshkind, Montecino-Rodriguez et al. 2009). We need to improve our knowledge on (i) the effects of genetic variability and aging, on lymphocyte dynamics population, repertoire selection and related immunodepression and (ii) the effects of immunosuppressive treatment in aged mice. Murine models may give some indications to better understand similar perturbations in humans or the ways to study and model them. In addition to aging that induces immunodepression, various clinical treatments used to control many diseases, induce immunosuppression. These treatments are designed to control unwanted immune responses, such as inflammation, autoimmunity, graft rejection, Graft Versus Host Disease (GVHD). Other treatments designed to fight cancer have the drawback to induce immunodepression since they target dividing (tumour) cells but they also kill the dividing cells from the immune system. The drawbacks of these treatments are their relative low specificity that impacts high dynamics biological system with high cell proliferation like lymphoid and haematopoietic systems. Aiming to understand the origins of immunodepression during aging or effects upon treatments but also the capacity of the immune system to regenerate should be coupled with the study of the immune system in homeostatic conditions. This requires specific investigation design related to system biology investigation and modelling.

These different levels of alteration with aging are related to the immune system complexity at inter- and intra-cell signalling, receptor diversity, clonotype selection and competition (Leitao, Freitas et al. 2009), fluid dissemination through the organism, homeostatic regulation and adaptation to a changing environment. In short, the immune system is a "complex system". In general, a complex system is comprised of a great number of heterogeneous entities, among which local interactions create multiple levels of collective structure and organization. Such systems require analysis at several spatial and temporal scales. Scientists are faced with radically new challenges when trying to observe, describe, control and develop original theories about these complex biological systems. We previously discussed concepts on the evaluation of multiscale systems dynamics, fluctuations, stability and resilience (Lavelle, Berry et al. 2008). In addition to looking to individual elements and isolated contexts, it is necessary to integrate information and devise more holistic approaches (Benoist, Germain et al. 2006; Cohn and Mata 2007). This is particularly true of the immune system (Cohen 2007). We recently delineated three 
challenges $^{1}$ to study the complexity of the immune systems: (i) the identification of lymphocyte populations, (ii) the reconstruction of their dynamics and repertoire selection process (iii) the mechanisms involved in the resilience or instabilities to perturbations, immune dysfunction in order to improve immuno-intervention strategies. It is obvious that the fluctuations related to aging that lead to progressive immunodepression or induced by therapeutic immunosuppression are both the consequence of the perturbations of the immune system and changes in the initial equilibrium state. Here, we moreover challenge the fact that immunosuppression during aging might increase the physiological immunodepression.

A number of studies aiming at providing a global analysis and comprehensive modelling of immunological systems have flourished around the world (Rangel, Angus et al. 2004; Braga-Neto and Marques 2006; Morel, Ta'asan et al. 2006; Petrovsky and Brusic 2006; Borghans and de Boer 2007; Chan and Kepler 2007; Efroni, Harel et al. 2007; Souza-e-Silva, Savino et al. 2009). We recently reported on methods and strategies to investigate lymphocyte dynamics and repertoires as well as the modelling concepts and formalism (Thomas-Vaslin \& al. in press). Moreover scientists are faced with data storage and sharing. The SIDR initiative to store data with metadata and share them is under current development as illustrated in the "T cell and aging" project ${ }^{2}$.

Interestingly, the high turnover and division of lymphocytes was revealed by the initial use of immunosuppressive drugs. In fact the early investigation of lymphoid cell dynamics and their precursors are related to the effects of perturbation induced by immunosuppression, as irradiation (Sprent, Anderson et al. 1974; Anderson, Olson et al. 1977; McLean and Michie 1995), following chemotherapy for cancer (Mackall, Fleisher et al. 1994) or other immunosuppressive drugs used to control the immune system. For example, Hydroyurea (HU) is a typical chemotherapy cytostatic treatment that non-specifically synchronizes all dividing cells and kills them. This drug particularly affects haematopoietic and lymphoid cells having high frequencies of cells in division and thus induces immunosuppressive effects. Experiments using HU allowed to reveal the reduced B cell functionality post-treatment in mice (Rusthoven and Phillips 1980). Such type of experiments and others like transfer experiment or labelling of dividing cells, were used to investigate population dynamics in the mouse and revealed the high turnover of B cells (Freitas, Rocha et al. 1982) reviewed in Freitas, Rocha et al. 1986). This high dynamic immune system display in fact internal activities observed in non-manipulated mice (Freitas, Pereira et al. 1989). We have also shown that the cellular environment determines the life-span of B cells by selection processes (Thomas-Vaslin and Freitas 1989). This drives clonal persistence of $\mathrm{B}$ cells through the variable region selection of the BCR (ThomasVaslin, Andrade et al. 1991), contributing to shape the B cell repertoire with aging (Andrade, Huetz et al. 1991). In T cells, similar HU immunosuppressive treatment revealed the short life expectancy, the continuous renewal and post thymic expansion of T cells (Rocha 1987). In fact, lymphocytes are under homeostatic control to regulate the growth and survival of $T$ and B cells that occupy and compete for different "ecological niches" (Freitas and Rocha 2000). Several other methods have allowed to explore $T$ cell dynamics by conditional ablation, using depleting antibodies (Qin, Wise et al. 1990; Waldmann and Cobbold 1998; Bourgeois and Stockinger 2006) chemical thymectomy (Bourgeois, Hao et al. 2008) or

\footnotetext{
${ }^{1} \mathrm{http}: / /$ roadmap.csregistry.org/tiki-index.php?page=From\%20molecules\%20to\%20organisms

${ }^{2}$ http:/ / sidr-dr.inist.fr/ fuge.jsp?idFuge $=301796$
} 
lymphocyte proliferation in immunocompromised recipients. This highly dynamical system makes it very sensible and reactive to antigen stimulations, but also to immunosuppressive treatments.

Moreover immunostimulatory and rejuvenation treatments are explored to stimulate the immune system in aging or after immunosuppression (Dudakov, Goldberg et al. 2009; Lynch, Goldberg et al. 2009). Several factors like Keratinocyte growth factor, Growth hormone, cytokines like IL-7, IL-15 or IL2, steroid hormones are implicated in aging process. Immuno-stimulatory pathways and rejuvenation treatments are experimented to prevent or revert the immunodepression (Zuniga-Pflucker and van den Brink 2007; Dorshkind, Montecino-Rodriguez et al. 2009; Mackall, Fry et al. 2011). In particular, some hormones like Growth Hormone $(\mathrm{GH})$ and Ghrelin stimulate thymic production, GH normalizing the $\mathrm{T}$ cell repertoire (Taub, Murphy et al. 2010).

\section{Immunosuppression \& aging: Some examples}

Our comprehension of processes of immunodepression with aging or effect of immunosuppression requires the understanding of lymphocyte dynamics and the global description of lymphocyte populations. The Figure 1 depicts hypothetical $\mathrm{T}$ cell population subsets in the thymus and peripheral organs, with cell division, process of selection and death, differentiation from one population to another one.

The investigation and modelling of cell population dynamics is often based on knowledge obtained from young individuals that can be considered at steady for a short time period in absence of intentional immunisation. Alterations of the system and observation of the responses to perturbations is also a way to understand the systems properties. As stated before, modelling cell population dynamics is an active field of research in systems immunology and a plenty of model of $\mathrm{T}$ cell dynamics have been proposed (Mehr, Globerson et al. 1995; Mehr, Perelson et al. 1997; Efroni, Harel et al. 2007; Asquith, Borghans et al. 2009; Dowling and Hodgkin 2009; Souza-e-Silva, Savino et al. 2009). Our mathematical model of $\mathrm{T}$ cell dynamics is based on a conveyor-belt model of differentiation (ThomasVaslin, Altes et al. 2008) as summarised below in Figure 4.

Here, we (1) give some examples of the effects of aging on $\mathrm{T}$ cell population composition and repertoire, (2) show the additive effects of transient or chronic immunosuppression, (3) investigated the effects of rejuvenation treatments on $\mathrm{T}$ cells repertoire.

\subsection{The physiological aging process \& genetic influence}

In order to quantify immunological alterations process through physiological aging we have studied the organ distribution, phenotype, repertoire and dynamics of T lymphocytes from young ( 2 months) to aged (25 months) mice. We have also evaluated the effect of genetic influences known to determine for example the CD4/CD8 ratio (Kraal, Weissman et al. 1983). Thus, two different mouse genetic backgrounds identified to provide various quality of repertoire selection and aging processes in non-manipulated lab mice C57BL/6 (B6) (H$\left.2^{b}\right)$ and FVB (H-2q) were used.

\subsubsection{T cell populations and cell counts}

Multicolour flow cytometry allows to define the phenotype of single cells and to identify thymocyte populations as $\mathrm{CD} 4^{\mathrm{lo}} \mathrm{CD} 8^{\text {lo }}(\mathrm{DN}), \mathrm{CD} 4^{\text {hi }} \mathrm{CD} 8^{\text {hi }}(\mathrm{DP})$ and mature T cell $\mathrm{CD} 4$ and 


\section{Complexity of lymphocyte population dynamics}
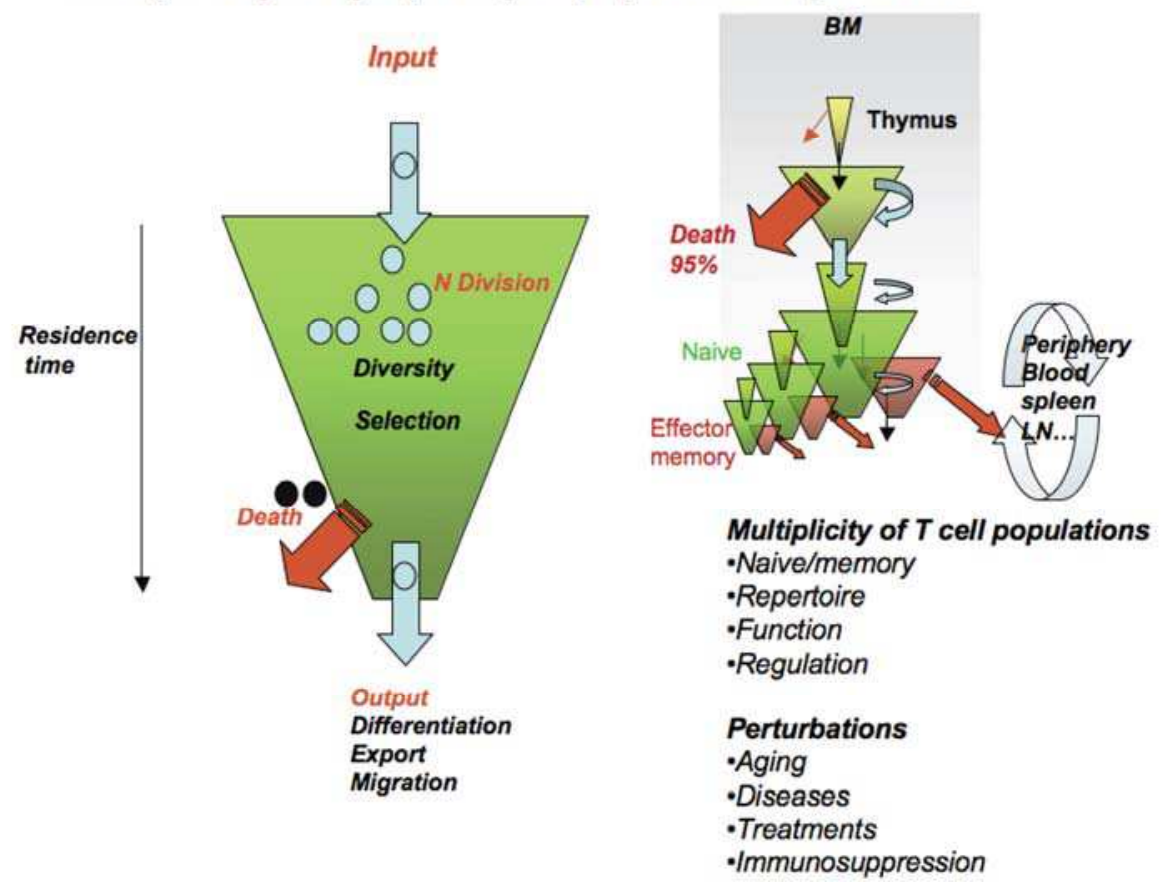

Fig. 1. Schematic hypothetical representation of $\mathrm{T}$ cell populations or compartments: a compartment could be considered as a green box, with input and output of cells. Inside a compartment, cells could be selected to proliferate or to die. In a central compartment such as the thymus, diversity of antigenic receptor is obtained by somatic gene rearrangements. Compartments could be multiplied according to tissue localisation, cell differentiation steps, cell function, receptor antigen repertoire expression... From a steady state equilibrium, perturbations can impact one particular or several compartments resizing them.

CD8 (Fig2A), representing the step of intrathymic T cell differentiation (see Fig. 4 below). From FACS we estimated cell percentages (Fig.2B) and numbers (Fig.2C). Similar identification of population in spleen and lymph nodes allows discriminating between CD4 or CD8 T cells and to estimate their percentages (Fig.2B) as well as the numbers of naïve T cells (with low CD44 expression) and antigen experienced cells (high CD44 expression) (Fig2.C). In young mice, the CD4 and CD8 percentages are characteristic of each lymphoid tissue as thymus, spleen, lymph nodes (Fig.2B). The variability between individuals is low, and a typical CD4/CD8 ratio is displayed according to genetic characteristics and organs (decreasing from 3.2 in thymus to 1.4 in lymph nodes in B6 mice, while from 5.0 to 2.1 in FVB). In old mice, this typical pattern is altered with high variability from mouse to mouse, increased proportion of either CD4 or CD8 T cells that correspond to clonal expansions of peripheral CD44hi $\mathrm{T}$ cells. Thymic involution is accelerated in FVB mice compared to B6 (Fig.2C) with a 10 times decrease of thymocyte number between 2 months to 2 years. The acceleration of thymic involution in FVB might be related to alteration of thymic epithelial cell differentiation (Nabarra, Mulotte et al. 2001) that in turn could affect the early 
differentiation of thymocytes. After thymic differentiation and selection, $\mathrm{T}$ lymphocytes reach peripheral organs as naïve CD44lo $\mathrm{T}$ cells, where they can encounter antigens. In the spleen, the number of naïve $\mathrm{T}$ cells decreases with aging due to decreased thymic production, while those of CD44hi $\mathrm{T}$ cells increased due to recruitment by antigenic stimulation. With aging the $\mathrm{T}$ cell population production is thus perturbed with less naïve production compensated in part by effector and memory $\mathrm{T}$ cell accumulation. Note that FVB young mice have twice the numbers of CD4 naïve T cells compared to B6, while other population looks quite similar, suggesting different selection processes and $\mathrm{T}$ cell population dynamics. With aging, alterations are higher in FVB due to the massive loss of naïve CD4 T cells while there is higher accumulation of CD8 CD44hi T cells. Thus, FVB mice display an accelerated "immunological aging" compared to B6 mice.

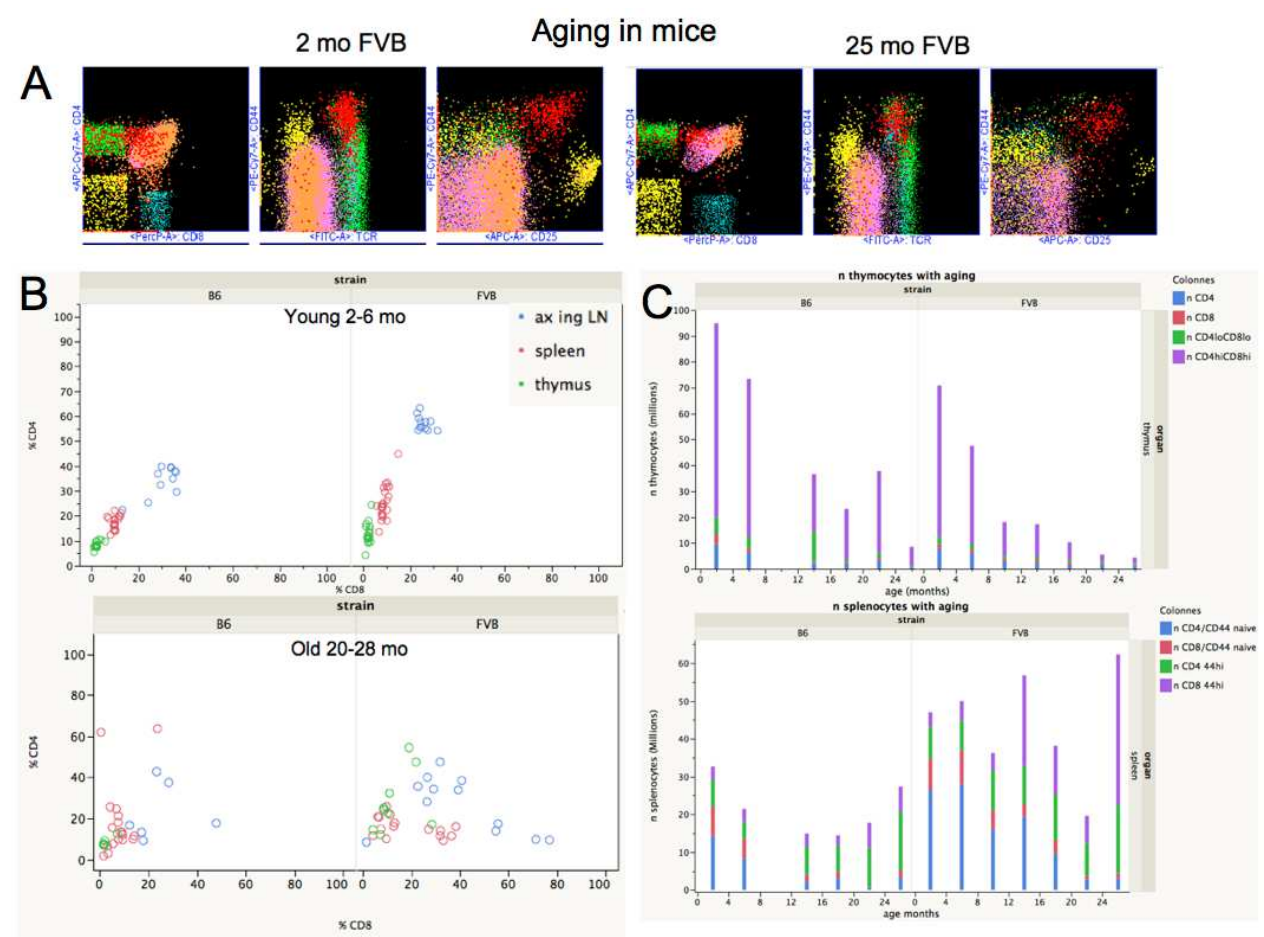

Fig. 2. Physiological aging in FVB and B6 mice: (A) Multicolour flow cytometry dot plot showing alterations of some cell populations in the thymus of 25 months old mouse compared to 2 months old mouse. (B) Percentages of CD4 and CD8 cells observed in thymus, spleen and lymph nodes from B6 or FVB in young or old mice. (C) Mean numbers of lymphocyte subpopulations in the thymus (upper part) and in the spleen (lower part) as a function of age. Graphs were done with JMP software.

\subsection{2 $\mathrm{T}$ cell repertoire diversity}

The diversity and variability of the TCR lymphocyte repertoire in young or old mice is an important point that is critical for the ability of an individual to respond to a huge variety of 
antigen. The potential diversity of $\mathrm{T}$ lymphocyte in mouse is estimated to $10^{15}$ while the size of splenic TCR repertoire is estimated to $2 \times 10^{6}$ with a clonal size of $30-40$ cells in young mice (Casrouge, Beaudoing et al. 2000). Although initially random rearrangement processes favour TCR diversity selection process, selection of particular TCR with germline encoded CDR1 and CDR2 sequence interacting with MHC also allows to control thymic selection (Scott-Browne, White et al. 2009; Jenkins, Chu et al. 2010). In B6, while there are Mammary tumour virus (Mtv) integrations in the genome, the absence of MHC II I-E expression avoids the superantigen presentation and prevents the deletion of some V $\beta$. Thus, in B6 mice the repertoire is very diversified compared to other strains that delete some V $\beta$ related to superantigen recognition. FVB has a TCR $\beta$ chromosomal deletion of V $\beta 8$ and 6 others V $\beta$ (Osman, Hannibal et al. 1999).

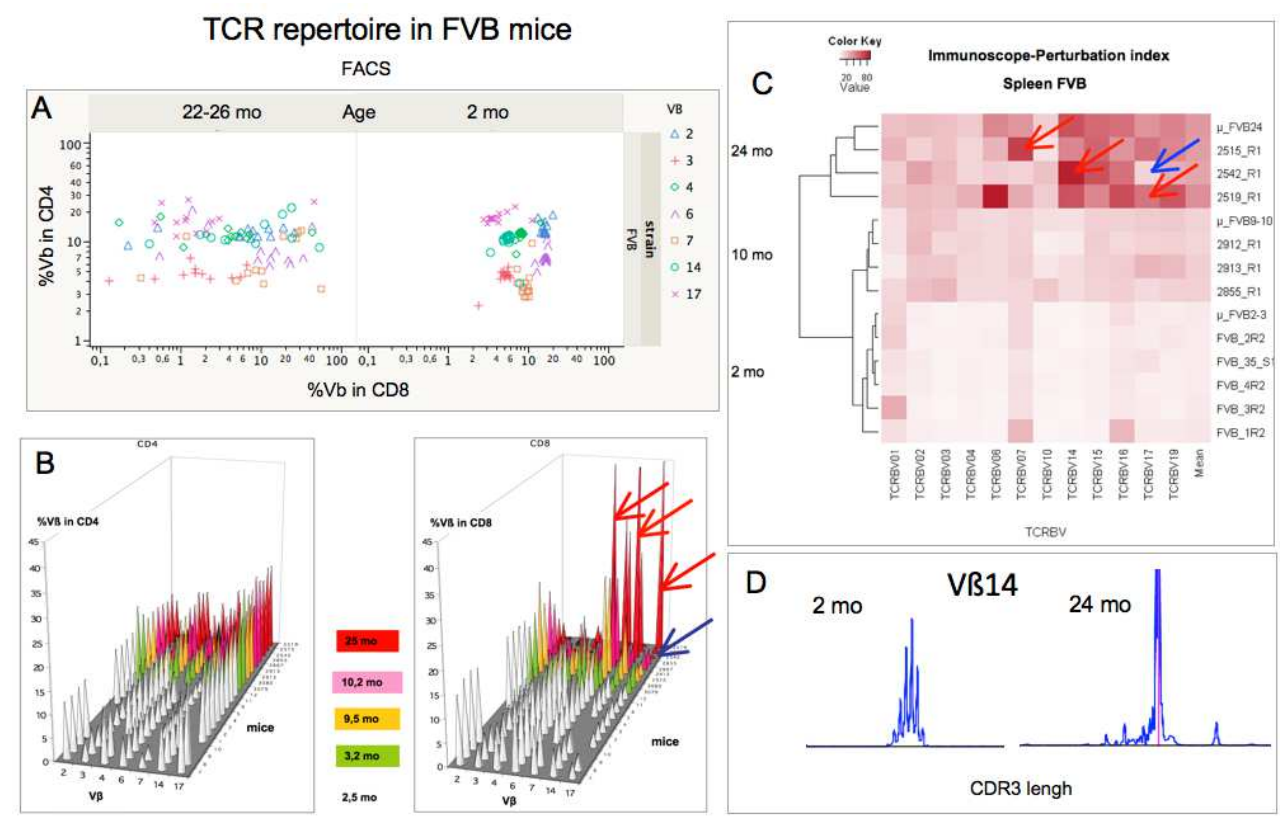

Fig. 3. Evolution of the TCR repertoire from FVB mice through ages in spleen. (A) Percentage of V $\beta$ in CD4 versus CD8 T cells in 2 months and 22-26 months old FVB mice estimated by FACS. (B) Percentage of VB in CD4 or CD8 T cells in various group of age by FACS, (C) Estimation of a perturbation index, with a double hierarchical classification following Immunoscope analysis, as exemplified by a V $\beta$ profile showing a Gaussian distribution of CDR3 length in young mice and an irregular profile with an oligoclonal expansion in 24 month old mice. The red arrows show clonal expansion in two-year old mice CD8 T cells. The blue arrow shows clonal deletion as revealed by FACS and Immunoscope in same mice

The TCR repertoire can be assessed either by FACS in individual CD4 or CD8 T cells with antibodies specific for each particular V $\beta$. Alternatively, Immunoscope analysis (Collette and Six 2002; Boudinot, Marriotti-Ferrandiz et al. 2008) allows measuring the variable length 
of the CDR3 region from the TCR involved in antigen recognition, for each V $\beta$ family and to estimate the diversity for each $\mathrm{V} \beta$. In young mice, we observed a very low variability in the TCR V $\beta$ splenocyte repertoire, as shown for FVB mice in Figure 3. A typical signature of young FVB mice can be observed by FACS or immunoscope. In contrast, variability is observed in old mice, with occurrence of CD8 CD44hi clonal expansion. This is confirmed by measuring CDR3 length expression by Immunoscope, as observance of non-Gaussian peak distribution. Some V $\beta$ clones also disappear in old mice. Thus, perturbations are important in old mice restricting the diversity of the repertoire, and consequently the possibility to respond to antigens. The $\mathrm{T}$ lymphocyte repertoire diversity shrinks due to clonal amplification and deletion as a consequence of the decrease of de novo thymic production and chronic antigenic stimulation by the environmental antigens (Kieper, Troy et al. 2005). The magnitude of these alterations depends on aging but also on genetic or epigenetic influences since in B6 mice the alterations seem less prominent (see Figure 8).

\subsection{Immunosuppression: The effect of transient conditional depletion of dividing $T$ cells on the immune system}

The depletion of dividing T cells leads to immunosuppression. This could be the result of an immunotherapy to control the reactivity of the $\mathrm{T}$ cells involved in immune responses (allograft rejection, Graft versus host disease, autoimmunity, inflammatory diseases), or the consequences of anti-tumour chemotherapy targeting dividing tumour cells. Experimental T cell depletion can also be used to estimate the natural division, turnover of $\mathrm{T}$ cells and to evaluate the homeostatic capacity of the immune system to reconstitute. We previously studied the effects of transient conditional immunosuppression through the killing of dividing $\mathrm{T}$ cells by different methods.

\subsubsection{Hydroxyurea}

As reviewed above, Hydroxyurea a cytostatic agent targeting dividing cells, has allowed to investigate renewal rates and differentiation of T cells and B cells (Rocha, Freitas et al. 1983; Cumano, Vieira et al. 1986; Penit and Vasseur 1988 ; Penit, Vasseur et al. 1988). We have shown that HU treatment also induces "immune amnesia", i.e. this immunosuppressive treatments kills lymphocytes involved in the memory maintenance process and thus the treatment prevents secondary memory immune response (Bellier, Thomas-Vaslin et al. 2003). Moreover, we showed that the depletion of dividing cells induced by HU provokes an homeostatic perturbation that displace effector/regulatory $\mathrm{T}$ cells ratio, inducing dominant transplantation tolerance (Giraud, Barrou et al. 2008). Thus, depleting dividing cells is a way to manipulate the immune system and immune responses.

\subsubsection{Pharmaco-genetic conditional immunosuppression}

To restrict the effect of chemotherapy to lymphocytes, engineering a specific conditional pharmaco-genetic immunosuppression in mice expressing the HSV1-TK suicide (TK) gene has allowed to achieve the ablation of B and T cell lineages (Heyman, Borrelli et al. 1989). To achieve specific $\mathrm{T}$ cell depletion we engineered mice expressing the suicide gene (TK+) under a CD4 enhancer and promoter: upon a nucleoside analogue as ganciclovir (GCV) treatment in these $\mathrm{TK}^{+}$transgenic mice, only the $\mathrm{CD} 4$ and $\mathrm{CD} 8 \mathrm{~T}$ cells that are in division are killed, while all other body cells can continue to divide. 


\section{Transient depletion of dividing $\mathrm{T}$ cells to evaluate $\mathrm{T}$ cells dynamics}

Using the TK/GCV strategy, we have shown the effect of transient (1 week) dividing T cells depletion followed by an homeostatic recovery of the various $\mathrm{T}$ cell subsets in the thymus and spleen of young adult mice. The mathematical modelling of these experimental data, showing depletion and repletion of $\mathrm{T}$ cells compartment led us to evaluate the impact of dividing cell depletion treatment on $\mathrm{T}$ cells, the time necessary to return to pre-treatment values. Moreover, it allows to estimate parameters values at the steady state describing the continuous $\mathrm{T}$ cell differentiation, fluxes, cell division in the thymus and spleen of young adult mice (Thomas-Vaslin, Altes et al. 2008). Figure 4 depicts the results of this model in young FVB mice and estimation of $\mathrm{T}$ cell composition in old mice from our experimental data.
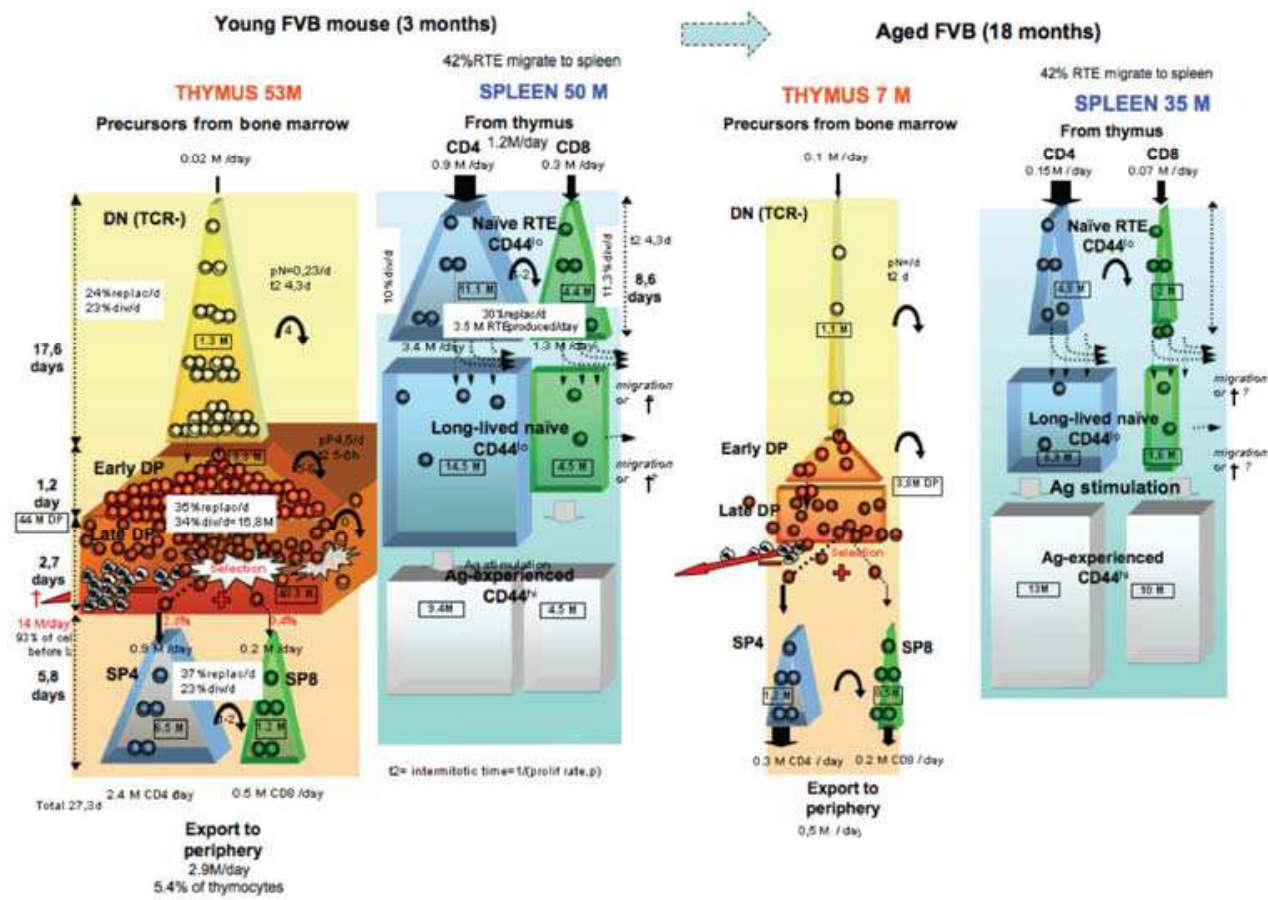

Fig. 4. T cell dynamics at steady state in young ( 3 months old) or middle aged (18 months old) FVB mice. The coloured boxes represent the cell populations (white boxes indicate Millions cells) differentiating from bone marrow precursors entering the thymus, the number of cell cycle (curved arrows), the time (days) for thymic differentiation (left shaded arrows) with transit through Double Negative CD4-CD8- (DN), Double Positive CD4+CD8+ (DP) submitted to selection process, and finally single positive CD4+CD8- or CD4-CD8+ (SP) stage. Then, recent thymic emigrants (RTE) enter the spleen, divide and fill the Long-Lived naïve compartment. Antigenic stimulations trigger naïve cells to differentiate in antigenexperimented T cells (details on the model are in Thomas-Vaslin, Altes et al. 2008). In old mice, the thymus was involuted, thus the naïve $\mathrm{T}$ cell is considerably reduced while the population of Ag-experiment $\mathrm{T}$ cells had increased following chronic antigenic challenges. 


\section{Transient depletion of dividing $\mathrm{T}$ cells induces the lack of immunological memory} maintenance

We have also studied the effects of a time controlled specific $\mathrm{T}$ cell depletion in immune mice, using the TK/GCV pharmacogenetic control and shown the lack of secondary immune response following such a treatment, confirming the effects observed with HU treatment (Bellier, Thomas-Vaslin et al. 2003).

\section{Depletion of dividing $\mathrm{T}$ cells induces memory amnesia}

First $\mathrm{H}-\mathrm{Y}$

Male skin graft

in B6 Females

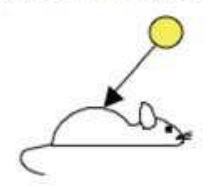

\section{Second H-Y}

Male skin graft

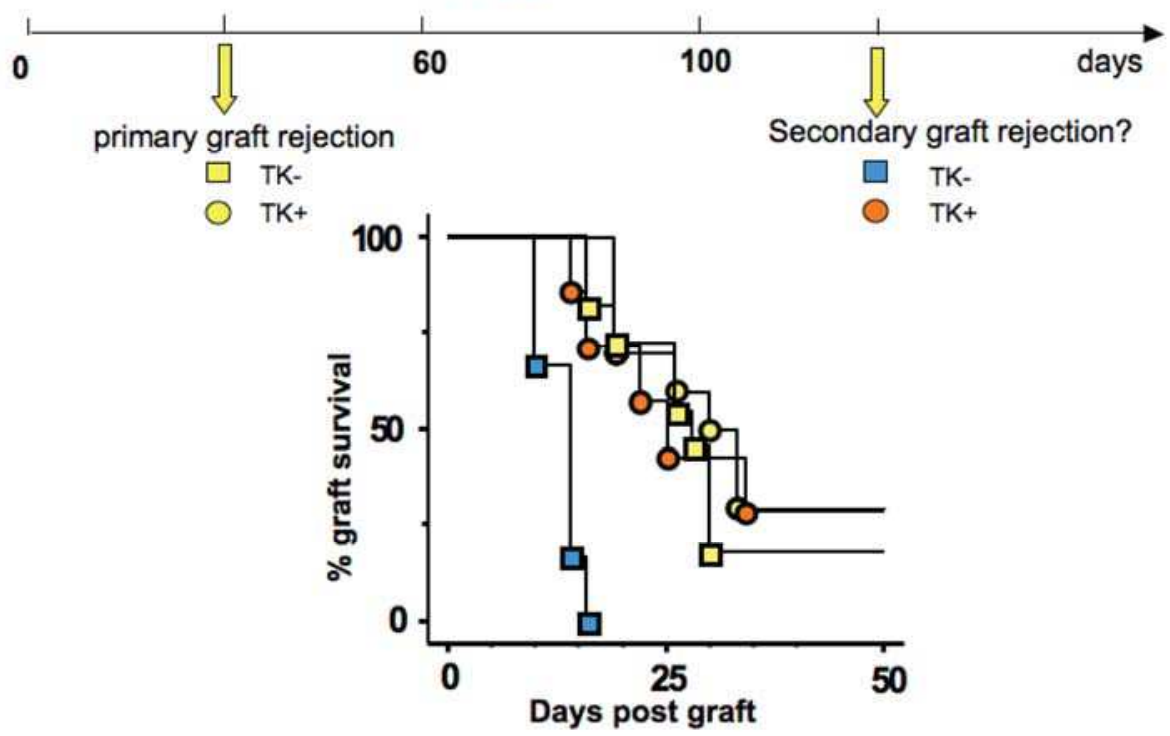

Fig. 5. Effect of immunosuppression on the immunological memory maintenance: B6 female mice were sensitized on day 0 to male skin antigen through a male skin graft. Female mice rejected this first male graft in about 30 days with a typical primary rejection kinetics (yellow symbols). After establishment of immune memory, the dividing T cells were depleted for 2 to 5 weeks. After cessation of treatment a second skin graft is performed and the kinetics of rejection is observed: in mice where the depletion of dividing T cells is inefficient (TK-GCV+) all skin grafts are rapidly rejected in less than 20 days, with a typical acceleration compatible with a second set kinetics (blue symbols). In mice where the depletion of dividing cells is efficient (TK+GCV+, orange symbols) the grafts are rejected with a primary set kinetics. 
Figure 5 depicts an example of $\mathrm{T}$ cell immune memory failure in the case of sensitisation with an allogeneic skin graft. Similar lack of memory responses were observed after the viral infection of mice with the lymphocytic choriomeningitis virus (LCMV). This demonstrates that immunological memory is maintained by a pool of T cells in constant division, which is sensible to some immunosuppressive treatments. This effect could be a drawback of immunosuppressant that might disturb the beneficial immune memory induced by vaccination. However, it also suggests that such immunosuppressive treatment could be used to target dividing cells responsible of undesirable memory $\mathrm{T}$ cell response (as in allograft sensitized recipient).

\section{Specific transient depletion of dividing $\mathrm{T}$ cells to control immunopathological $\mathrm{T}$ cell responses}

Used in pathological situations, the conditional pharmacogenetic immunosuppression induced by the TK/GCV system allows to (i) transiently control LCMV infection (Boyer, Cohen et al. 2000). (ii) control GVHD (Cohen, Boyer et al. 1997; Cohen, Boyer et al. 1999; Cohen, Boyer et al. 1999; Cohen, Saron et al. 2000; Cohen, Boyer et al. 2001). Clinical protocol associated with injection of regulatory $\mathrm{T}$ cells expressing the TK gene as a safety gene to control GVHD are under assessment (Guillot-Delost, Cherai et al. 2008). Applied upon an allograft this treatment allows delayed rejection (skin graft) or tolerance of the graft (vascularized heart allograft) (Braunberger, Cohen et al. 2000; Braunberger, RaynalRaschilas et al. 2000; Thomas-Vaslin, Bellier et al. 2000). In fact, we further showed that the depletion treatment (either $\mathrm{HU}$ or TK/GCV) induces disequilibrium favouring regulatory $\mathrm{T}$ cells (Treg) responsible for dominant tolerance able to control islet pancreatic allografts rejection (Giraud, Barrou et al. 2008). While aging by itself leads to multilevel alterations and finally immunodepression at biological level, little is know about the additive effect of clinical immunosuppression during aging. Observations that allograft rejection is decreased in old recipient lead to recommendations that older recipient may require less immunosuppression than young patients to control allograft rejection and to treat autoimmunity or inflammation diseases (Bradley 2002).

\section{Effect of transient depletion of dividing $T$ cells according to age}

We have compared the kinetics of $\mathrm{T}$ cells in mice during and after a transient depletion of dividing $\mathrm{T}$ cells according to the age of the mice. In young adult mice, the immunosuppressive treatment applied during two weeks initially induces the depletion of naïve T (CD44 $\left.{ }^{\mathrm{lo}}\right)$ cells in FVB mice and in both naïve and effector/memory (CD44hi) T cell in B6 mice (Figure 6).

Then, homeostatic recovery occurs within two months and both strains recovered initial $\mathrm{T}$ lymphocyte counts. In contrast, in aged mice the two weeks ganciclovir treatment induces in FVB a continuous decrease of naïve $T$ cells counts while effector/memory $T$ cells accumulate. In B6 mice the GCV treatment induces less perturbation probably because the thymic involution is less prominent than in FVB at the same age. Thus reconstitution of naïve $\mathrm{T}$ cells can occur post treatment, while accumulation of effector/memory T cells is limited.

The use of conditional pharmacogenetic immunosuppression has allowed proposing the model depicted in Figure 4 from mathematical modelling. Visual computer modelling of $\mathrm{T}$ cell population dynamics is currently under progress (McEwan, Bersini et al. 2011; McEwan, Bersini et al. 2011) to develop our comprehension of cell fluxes between cell compartment and organs, cell division. This modelling should allow quantifying parameter values in young to aged mice at steady state, but also simulating some treatments, to confirm our experimental observations and hypothesis. 


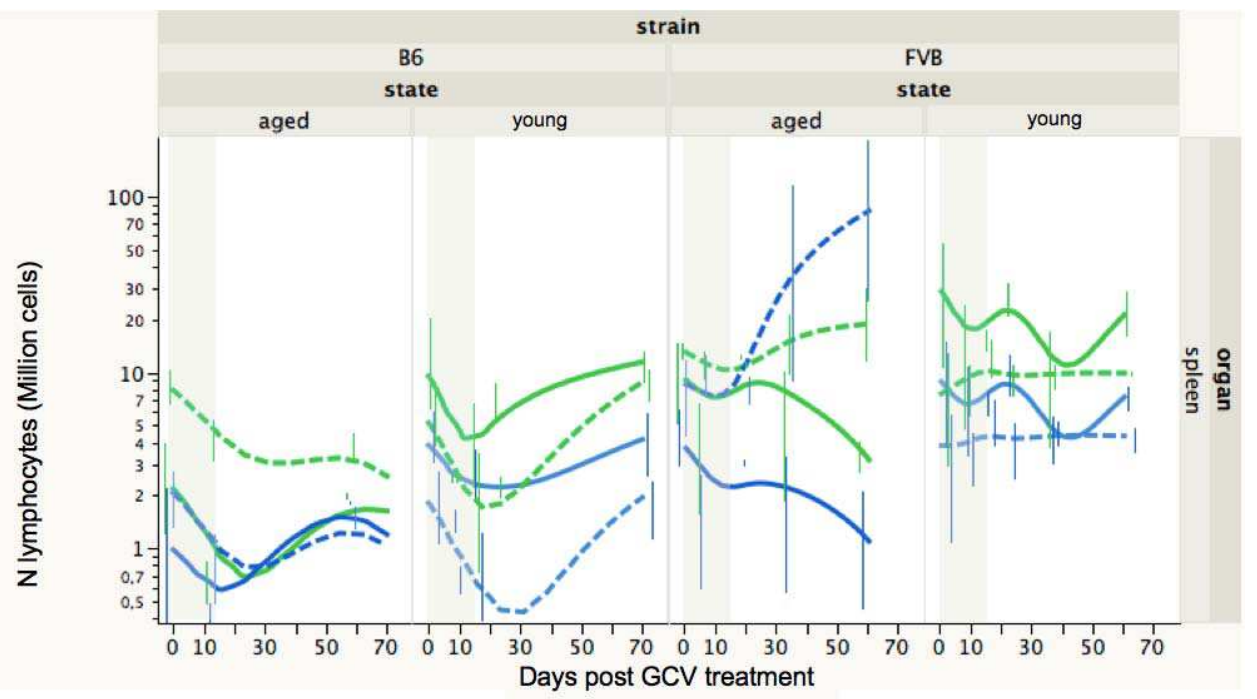

Fig. 6. Effect of transient pharmacogenetic immunosuppression in the spleen of transgenic B6 or FVB mice expressing the HSV1-TK suicide gene in the T cell lineage. Ganciclovir treatment is applied for 14 days (grey area) in young ( 2 months old) or aged (18 months old) mice. Box plot and spline curves show the numbers of CD4 CD44lo (continuous green line), CD8 CD44to (continuous blue line), CD4CD44hi (dashed green line) CD8CD44hi (dashed blue line) $\mathrm{T}$ cells.

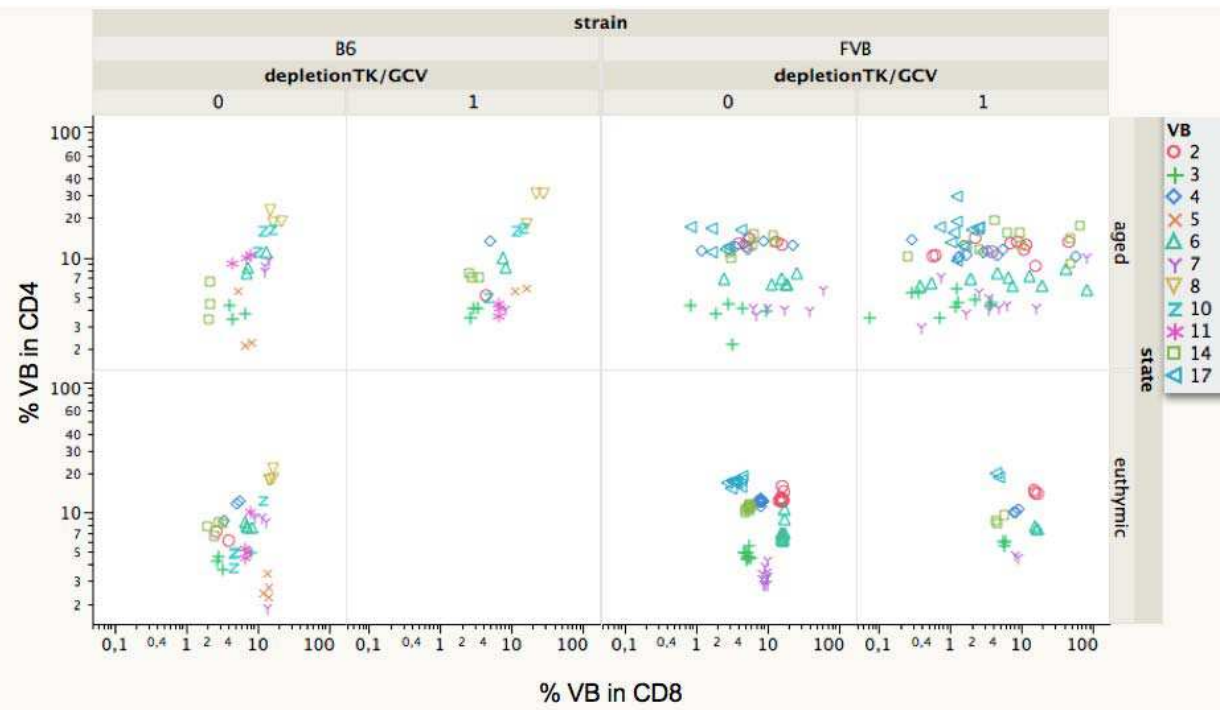

Fig. 7. VB TCR repertoire by FACS of spleen cells, showing the percentage of each VB in CD4 vs CD8 T cells, in controls TK-GCV+, TK+GCV- and TK-GCV- mice (TK/GCV depletion $=0)$ and in depletion sensitive $\mathrm{TK}^{+} \mathrm{GCV}+$ mice $(\mathrm{TK} / \mathrm{GCV}$ depletion $=1)$. 
The analysis of the TCR VB repertoire following the pharmacogenetic immunosuppression (Figure 7) revealed major alterations in the CD8 T cells from aged FVB mice with either oligoclonal expansion (representing up to 60 millions of cells) or partial clonal deletion (manuscript in preparation). In contrast, in B6 mice the alterations following treatment are more limited although detectable. Again the slower "immunological aging" of B6 mice seems to preserve homeostatic recovery and the T cell repertoire diversity.

\subsection{Prevention of aging and immunodepression}

IL-2 has been shown to have a dual role in CD8 memory maintenance, being able to inhibit the proliferation of CD8 memory T cells (Dai, Konieczny et al. 2000) via down regulation of the $\gamma_{c}$ chain expression of its receptor, increasing apoptotic cell death (Li, Demirci et al. 2001). The growth of very large CD8 T cell clones observed in old mice was attributed to cytokine deregulation, IL-15 being stimulatory, while IL-2 is inhibitory (Ku, Kappler et al. 2001). IL-2 is a cytokine that acts centrally and peripherally to increase CD4 naïve T cell numbers (Foussat, Bouchet-Delbos et al. 2004). There is a defect of IL-2 production by CD4 T cells from aged mice, reducing their expansion capacity (Haynes, Linton et al. 1999). IL-2 is also necessary to maintain $\mathrm{CD}^{+} \mathrm{CD} 25^{+}$regulatory $\mathrm{T}$ cells that control $\mathrm{CD} 4 \mathrm{~T}$ cell homeostasis (Almeida, Legrand et al. 2002). $\mathrm{CD} 4{ }^{+} \mathrm{CD} 25^{+}$regulatory $\mathrm{T}$ cells are involved in IL-2 mediated inhibition of memory CD8 T cells, reducing their division (Murakami, Sakamoto et al. 2002).

Regulatory $\mathrm{T}$ cells were shown to accumulate with aging contributing to decrease immune responses. However the augmentation of suppressive function is not due to $\mathrm{CD}^{+}{ }^{+} \mathrm{CD} 25^{+} \mathrm{Foxp}^{+} \mathrm{T}$ cells but to $\mathrm{CD}^{+} \mathrm{CD} 25^{-}$Foxp3+ $\mathrm{T}$ cells that appear with aging (Nishioka, Shimizu et al. 2006). Since a lack of IL-2 secretion is reported in old individuals, with deficiency in CD4 help, IL-2 treatments were assessed and shown to increase Treg cell numbers in lymphopenic individuals (Zhang, Chua et al. 2005). The role of Treg in the prevention of repertoire alteration was also shown in the case of lymphopenia induced proliferation (Winstead, Reilly et al.). Treg also modulate the effector function of CD8 by competing for IL-2 (McNally, Hill et al. 2011). IL-2 also has positive effect to control T cell homeostasis in autoimmunity (Humrich, Morbach et al.). In NOD type-1 diabetic mice, IL2 can prevent or reverse autoimmunity, by stimulation of Tregs (Grinberg-Bleyer, Baeyens et al.). In infectious diseases, HIV infected patient IL-2 treatment induces an increase of thymic export (Carcelain, Saint-Mezard et al. 2003) and induces a peripheral CD4 T cell expansion by limiting CD4 proliferation and increasing CD4CD25+ subset (Sereti, Anthony et al. 2004).

To prevent the effects of aging homeostatic deregulation and TCR repertoire alterations, we tested the effect of IL-2 or transfer of regulatory T cells (CD4+CD25+) injected in middleaged B6 mice (15-month old) (Figure 8). Both treatments prevent clonal alterations as revealed by FACS analysis of TCRVB repertoire at the age of 24-28 months. Non-treated B6 mice developed by 24-28 months oligoclonal expansions essentially in CD4 T cells and loose CD8 T cell clones. IL-2 treated mice have lower CD4 clonal expansions, that are absent in Treg treated mice and repertoire looks "younger". Both treatments limited the decrease of CD8 cell clones. Note that at variance with FVB mice, in B6 mice the aging of the repertoire is delayed, and that oligoclonal expansions concern mostly CD4 T cells in B6 but CD8 T cells in FVB. 


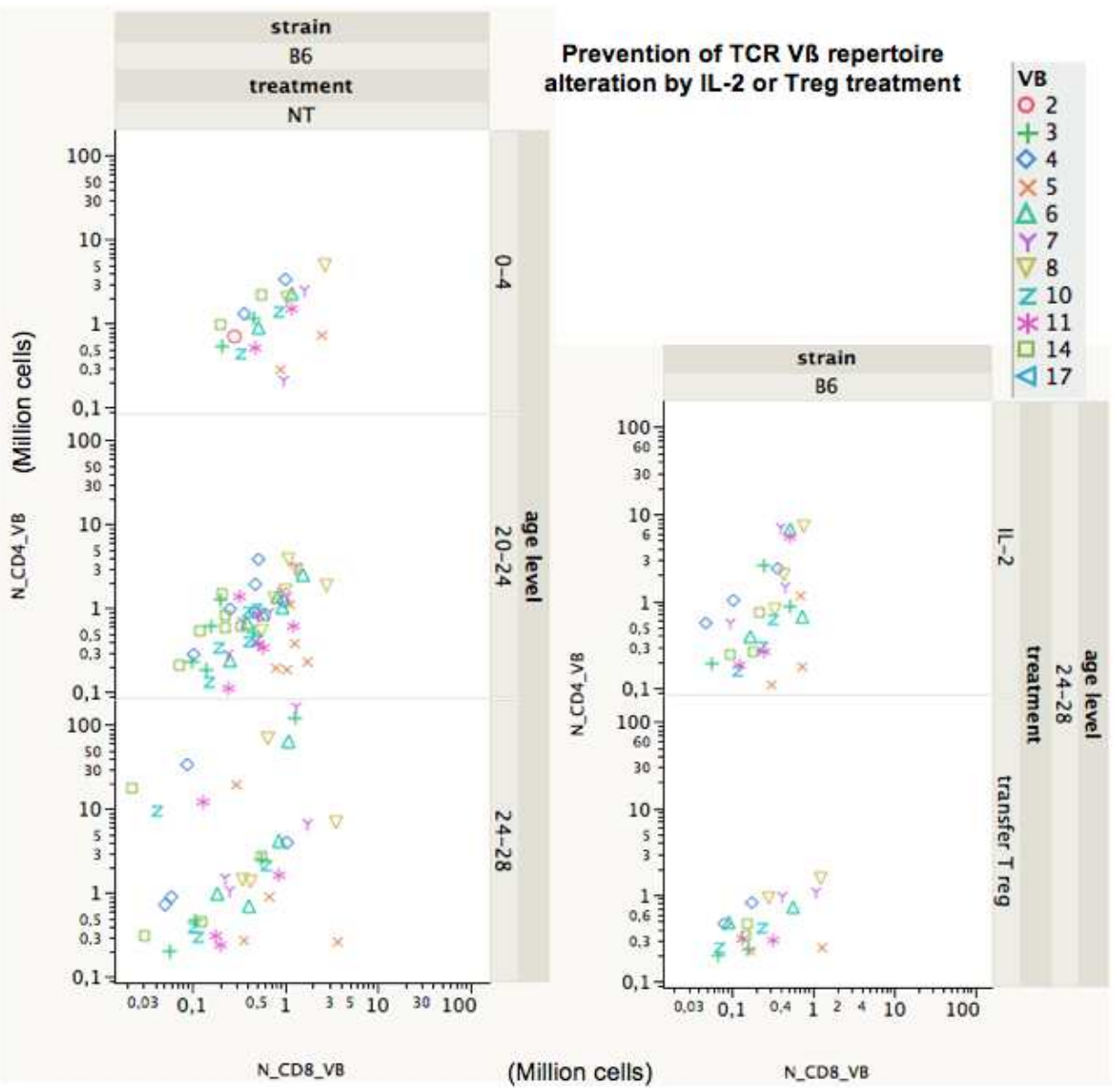

Fig. 8. VB TCR repertoire by FACS of spleen cells from B6 mice, showing the number of each $\mathrm{VB}$ in CD4 vs. CD8 T cells, in non treated B6 mice according to age, and in B6 mice that received an IL-2 treatment or an injection of regulatory T cells (CD25+) at the age of 15 months and are analysed at the age of 24-28 months.

\section{Conclusions}

We pointed out that the different initial $\mathrm{T}$ cell numbers available according to age and genetic background determines the kinetics of depletion and recovery in B6 and FVB mice. This suggests that the $\mathrm{T}$ cell dynamics and turnover differs according to genetic influence. FVB mice have an accelerated immunological aging, with accelerated thymic involution and finally accumulation of CD8 clonal T cell expansions by 22 months. The transient depletion of dividing $\mathrm{T}$ cells temporarily disturb the dynamic $\mathrm{T}$ cell equilibrium of young mice of both genetic background, with a return to steady-state values and no alteration in repertoire diversity. However, in middle-aged mice the effect of the transient depletion can be more dramatic: in FVB mice it leads to accelerated occurrence of CD8 T cell clones. In B6 mice, the 
long term consequences of treatment are less important, most likely because the thymus is more productive at the same age. However, we also observed that a preventive treatment by serial injection of IL-2 or a single injection of Treg cells in middle aged mice can successfully prevent the natural occurrence of repertoire alterations.

Our work allows us to observe the physiological aging that impacts on the quality and quantity of $\mathrm{T}$ cells in the central and peripheral organs as well as on the diversity of the repertoire. It indicates that some immunosuppressive treatments inducing a homeostatic disturbance of the immune systems might accelerate the aging of the $\mathrm{T}$ cell composition and reduce the TCR repertoire diversity, while some immunostimulatory treatment or regulatory $\mathrm{T}$ cells might prevent such alterations. As underlined before, several biological scales are involved in these processes and the variability observed between genetic background, ages of the same individual at the level of cell population, cells or TCR cellular or molecular repertoire have to be evaluated.

Use of systems immunology approaches as multidimensional statistical models (Pham, in preparation) and computer models (McEwan, in preparation) are novel approaches that will give a more thorough evaluation of complex $\mathrm{T}$ cell population dynamics to be able to simulate the physiological behaviour and effects of perturbations.

\section{Acknowledgments}

We thank the financial supports from INSERM ATC vieillissement, CNRS Programme Interdisciplinaire Longévité \& Vieillissement, Emergence UPMC. PP is recipient of Ph.D. fellowship ED CDV, Ministry of Research. We thanks the Centre d'Experimentation Fonctionnelle Pitié-Salpétrière, Paris for the long term care of our old mice.

\section{References}

(2005). Aging and the immune system. Curr Opin Immunol 17: 455-.

(2009). Immune senescence special issue. Trends Immunol 30(7): 293-382.

Ahmed, M., K. G. Lanzer, et al. (2009). Clonal expansions and loss of receptor diversity in the naive CD8 T cell repertoire of aged mice. J Immunol 182(2): 784-92.

Almeida, A. R., N. Legrand, et al. (2002). Homeostasis of peripheral CD4+ T cells: IL-2R alpha and IL-2 shape a population of regulatory cells that controls CD4+ T cell numbers. J Immunol 169(9): 4850-60.

Anderson, R. E., G. B. Olson, et al. (1977). Radiosensitivity of T and B lymphocytes. IV. Effect of whole body irradiation upon various lymphoid tissues and numbers of recirculating lymphocytes. J Immunol 118(4): 1191-200.

Andrade, L., F. Huetz, et al. (1991). Biased VH gene expression in murine CD5 B cells results from age-dependent cellular selection. Eur J Immunol 21(9): 2017-23.

Andrew, D. and R. Aspinall (2001). Il-7 and not stem cell factor reverses both the increase in apoptosis and the decline in thymopoiesis seen in aged mice. J Immunol 166(3): 1524-30.

Aspinall, R. and J. J. Goronzy (2010). Immune senescence. Curr Opin Immunol 22(4): 497-9.

Asquith, B., J. A. Borghans, et al. (2009). Lymphocyte kinetics in health and disease. Trends Immunol 30(4): 182-9.

Bellier, B., V. Thomas-Vaslin, et al. (2003). Turning immunological memory into amnesia by depletion of dividing T cells. Proc Natl Acad Sci U S A 100(25): 15017-15022. 
Benoist, C., R. N. Germain, et al. (2006). A plaidoyer for 'systems immunology'. Immunol Rev 210: 229-34.

Blackman, M. A. and D. L. Woodland (2011). The narrowing of the CD8 T cell repertoire in old age. Curr Opin Immunol 23: 1-6.

Borghans, J. A. and R. J. de Boer (2007). Quantification of T-cell dynamics: from telomeres to DNA labeling. Immunol Rev 216: 35-47.

Boudinot, P., M. E. Marriotti-Ferrandiz, et al. (2008). New perspectives for large-scale repertoire analysis of immune receptors. Mol Immunol 45(9): 2437-45.

Bourgeois, C., Z. Hao, et al. (2008). Ablation of thymic export causes accelerated decay of naive CD4 $\mathrm{T}$ cells in the periphery because of activation by environmental antigen. Proc Natl Acad Sci U S A 105(25): 8691-6.

Bourgeois, C. and B. Stockinger (2006). CD25+CD4+ regulatory T cells and memory T cells prevent lymphopenia-induced proliferation of naive $\mathrm{T}$ cells in transient states of lymphopenia. J Immunol 177(7): 4558-66.

Boursalian, T. E., J. Golob, et al. (2004). Continued maturation of thymic emigrants in the periphery. Nat Immunol 5(4): 418-25.

Boyer, O., J. L. Cohen, et al. (2000). Transient control of a virus-induced immunopathology by genetic immunosuppression. Gene Ther 7(18): 1536-42.

Bradley, B. A. (2002). Rejection and recipient age. Transpl Immunol 10(2-3): 125-32.

Braga-Neto, U. M. and E. T. Marques, Jr. (2006). From functional genomics to functional immunomics: new challenges, old problems, big rewards. PLoS Comput Biol 2(7): e81.

Braunberger, E., J. L. Cohen, et al. (2000). T-Cell suicide gene therapy for organ transplantation: induction of long-lasting tolerance to allogeneic heart without generalized immunosuppression. Mol Ther 2(6): 596-601.

Braunberger, E., N. Raynal-Raschilas, et al. (2000). Tolerance induced without immunosuppression in a T-lymphocyte suicide-gene therapy cardiac allograft model in mice. J Thorac Cardiovasc Surg 119(1): 46-51.

Carcelain, G., P. Saint-Mezard, et al. (2003). IL-2 therapy and thymic production of naive CD4 T cells in HIV-infected patients with severe CD4 lymphopenia. Aids 17(6): 841-50.

Casrouge, A., E. Beaudoing, et al. (2000). Size estimate of the alpha beta TCR repertoire of naive mouse splenocytes. J Immunol 164(11): 5782-7.

Chan, C. and T. B. Kepler (2007). Computational immunology--from bench to virtual reality. Ann Acad Med Singapore 36(2): 123-7.

Ciupe, S. M., B. H. Devlin, et al. (2009). The dynamics of T-cell receptor repertoire diversity following thymus transplantation for DiGeorge anomaly. PLoS Comput Biol 5(6): e1000396.

Clambey, E. T., J. W. Kappler, et al. (2007). CD8 T cell clonal expansions \& aging: a heterogeneous phenomenon with a common outcome. Exp Gerontol 42(5): 40711.

Clambey, E. T., L. F. van Dyk, et al. (2005). Non-malignant clonal expansions of CD8+ memory T cells in aged individuals. Immunol Rev 205: 170-89.

Cohen, I. R. (2007). Modeling immune behavior for experimentalists. Immunol Rev 216: 2326. 
Cohen, J. L., O. Boyer, et al. (1999). Would suicide gene therapy solve the T-cell dilemma of allogeneic bone marrow transplantation ? Immunol Today 20(4): 172-176.

Cohen, J. L., O. Boyer, et al. (2001). Suicide gene therapy of graft-versus-host disease: immune reconstitution with transplanted mature T cells. Blood 98(7): 2071-6.

Cohen, J. L., O. Boyer, et al. (1997). Prevention of graft-versus-host disease in mice using a suicide gene expressed in T lymphocytes. Blood 89(12): 4636-45.

Cohen, J. L., O. Boyer, et al. (1999). Suicide gene-mediated modulation of graft-versus-host disease [In Process Citation]. Leuk Lymphoma 34(5-6): 473-80.

Cohen, J. L., M. F. Saron, et al. (2000). Preservation of graft-versus-infection effects after suicide gene therapy for prevention of graft-versus-host disease. Hum Gene Ther 11(18): 2473-81.

Cohn, M. and J. Mata (2007). Quantitative modeling of immune response. Imm. Rev. 216: 1236.

Collette, A. and A. Six (2002). ISEApeaks: an Excel platform for GeneScan and Immunoscope data retrieval, management and analysis. Bioinformatics 18(2): 32930.

Cumano, A., P. Vieira, et al. (1986). Effects of hydroxyurea in vivo treatment on the antibody response in mice. Ann Inst Pasteur Immunol 137D(3): 355-67.

Dai, Z., B. T. Konieczny, et al. (2000). The dual role of IL-2 in the generation and maintenance of CD8+ memory T cells. J Immunol 165(6): 3031-6.

Dorshkind, K., E. Montecino-Rodriguez, et al. (2009). The ageing immune system: is it ever too old to become young again? Nat Rev Immunol 9(1): 57-62.

Dowling, M. R. and P. D. Hodgkin (2009). Modelling naive T-cell homeostasis: consequences of heritable cellular lifespan during ageing. Immunol Cell Biol 87(6): 445-56.

Dudakov, J. A., G. L. Goldberg, et al. (2009). Sex steroid ablation enhances hematopoietic recovery following cytotoxic antineoplastic therapy in aged mice. J Immunol 183(11): 7084-94.

Efroni, S., D. Harel, et al. (2007). Emergent dynamics of thymocyte development and lineage determination. PLoS Comput Biol 3(1): e13.

Ferrando-Martinez, S., E. Ruiz-Mateos, et al. Age-related deregulation of naive $\mathrm{T}$ cell homeostasis in elderly humans. Age (Dordr) 33(2): 197-207.

Foussat, A., L. Bouchet-Delbos, et al. (2004). Effects of exogenous IL-2 administration on the homeostasis of CD4+ T lymphocytes. J Clin Immunol 24(5): 503-14.

Freitas, A., P. Pereira, et al. (1989). B cell activities in normal unmanipulated mice. Contrib Microbiol Immunol 11: 1-26.

Freitas, A. A. and B. Rocha (2000). Population biology of lymphocytes: the flight for survival. Annu Rev Immunol 18: 83-111.

Freitas, A. A., B. Rocha, et al. (1986). Lymphocyte population kinetics in the mouse. Immunol. Rev. 91: 5.

Freitas, A. A., B. Rocha, et al. (1982). Population dynamics of B lymphocytes and their precursors: demonstration of high turnover in the central and peripheral lymphoid organs. J. Immunol. 128: 54-60.

Giraud, S., B. Barrou, et al. (2008). Transient Depletion of Dividing T Lymphocytes in Mice Induces the Emergence of Regulatory $\mathrm{T}$ Cells and Dominant Tolerance to Islet Allografts. Am J Transplant 8: 1-12. 
Goronzy, J. J. and C. M. Weyand (2005). T cell development and receptor diversity during aging. Curr Opin Immunol 17(5): 468-75.

Gress, R. E. and S. G. Deeks (2009). Reduced thymus activity and infection prematurely age the immune system. J Clin Invest 119(10): 2884-7.

Grinberg-Bleyer, Y., A. Baeyens, et al. IL-2 reverses established type 1 diabetes in NOD mice by a local effect on pancreatic regulatory T cells. J Exp Med 207(9): 1871-8.

Guillot-Delost, M., M. Cherai, et al. (2008). Clinical-grade preparation of human natural regulatory $\mathrm{T}$-cells encoding the thymidine kinase suicide gene as a safety gene. $\mathrm{J}$ Gene Med 10(8): 834-46.

Hale, J. S., T. E. Boursalian, et al. (2006). Thymic output in aged mice. Proc Natl Acad Sci U S A 103(22): 8447-52.

Haynes, L., P. J. Linton, et al. (1999). Interleukin 2, but not other common gamma chainbinding cytokines, can reverse the defect in generation of CD4 effector T cells from naive T cells of aged mice. J Exp Med 190(7): 1013-24.

Heyman, R. A., E. Borrelli, et al. (1989). Thymidine kinase obliteration: creation of transgenic mice with controlled immune deficiency. Proc Natl Acad Sci U S A 86(8): 2698-702.

Houston, E. G., Jr., L. E. Higdon, et al. (2011). Recent thymic emigrants are preferentially incorporated only into the depleted T-cell pool. Proc Natl Acad Sci U S A 108(13): 5366-71.

Humrich, J. Y., H. Morbach, et al. Homeostatic imbalance of regulatory and effector T cells due to IL-2 deprivation amplifies murine lupus. Proc Natl Acad Sci U S A 107(1): 204-9.

Jenkins, M. K., H. H. Chu, et al. (2010). On the composition of the preimmune repertoire of T cells specific for Peptide-major histocompatibility complex ligands. Annu Rev Immunol 28: 275-94.

Kieper, W. C., A. Troy, et al. (2005). Recent immune status determines the source of antigens that drive homeostatic T cell expansion. J Immunol 174(6): 3158-63.

Kraal, G., I. L. Weissman, et al. (1983). Genetic control of T-cell subset representation in inbred mice. Immunogenetics 18(6): 585-92.

$\mathrm{Ku}, \mathrm{C}$. C., J. Kappler, et al. (2001). The growth of the very large CD8+ T cell clones in older mice is controlled by cytokines. J Immunol 166(4): 2186-93.

Lavelle, C., H. Berry, et al. (2008). From molecules to organisms: towards multiscale integrated models of biological systems. Theoretical Biology Insights 1: 13-22.

Leitao, C., A. A. Freitas, et al. (2009). The role of TCR specificity and clonal competition during reconstruction of the peripheral T cell pool. J Immunol 182(9): 5232-9.

LeMaoult, J., I. Messaoudi, et al. (2000). Age-related dysregulation in CD8 T cell homeostasis: kinetics of a diversity loss. J Immunol 165(5): 2367-73.

Li, X. C., G. Demirci, et al. (2001). IL-15 and IL-2: a matter of life and death for T cells in vivo. Nat Med 7(1): 114-8.

Lynch, H. E., G. L. Goldberg, et al. (2009). Thymic involution and immune reconstitution. Trends Immunol 30(7): 366-73.

Mackall, C. L., T. A. Fleisher, et al. (1994). Lymphocyte depletion during treatment with intensive chemotherapy for cancer. Blood 84(7): 2221-8.

Mackall, C. L., T. J. Fry, et al. (2011). Harnessing the biology of IL-7 for therapeutic application. Nat Rev Immunol 11(5): 330-42. 
McEwan, C. H., H. Bersini, et al. (2011). A computational technique to scale mathematical models towards complex heterogeneous systems COSMOS workshop ECAL 2011 Conference, Paris, Luniver Press.

McEwan, C. H., H. Bersini, et al. (2011). Refitting Harel statecharts for systemic mathematical models in computational immunology. 10th International Conference on

Artificial Immune Systems (ICARIS), Cambridge.

McLean, A. R. and C. A. Michie (1995). In vivo estimates of division and death rates of human T lymphocytes. Proc Natl Acad Sci U S A 92(9): 3707-11.

McNally, A., G. R. Hill, et al. (2011). CD4+CD25+ regulatory T cells control CD8+ T-cell effector differentiation by modulating IL-2 homeostasis. Proc Natl Acad Sci U S A 108(18): 7529-34.

Mehr, R., A. Globerson, et al. (1995). Modeling positive and negative selection and differentiation processes in the thymus. J Theor Biol 175(1): 103-26.

Mehr, R., A. S. Perelson, et al. (1997). Regulatory feedback pathways in the thymus. Immunol Today 18(12): 581-5.

Messaoudi, I., J. Lemaoult, et al. (2004). Age-related CD8 T cell clonal expansions constrict CD8 T cell repertoire and have the potential to impair immune defense. J Exp Med 200(10): 1347-58.

Morel, P. A., S. Ta'asan, et al. (2006). New insights into mathematical modeling of the immune system. Immunol Res 36(1-3): 157-65.

Murakami, M., A. Sakamoto, et al. (2002). CD25+CD4+ T cells contribute to the control of memory CD8+ T cells. Proc Natl Acad Sci U S A 99(13): 8832-7.

Nabarra, B., M. Mulotte, et al. (2001). Ultrastructural study of the FVB/N mouse thymus: presence of an immature epithelial cell in the medulla and premature involution. Dev Comp Immunol 25(3): 231-43.

Nishioka, T., J. Shimizu, et al. (2006). CD4+CD25+Foxp3+ T cells and CD4+CD25-Foxp3+ T cells in aged mice. J Immunol 176(11): 6586-93.

Osman, G. E., M. C. Hannibal, et al. (1999). FVB/N (H2(q)) mouse is resistant to arthritis induction and exhibits a genomic deletion of T-cell receptor $\mathrm{V}$ beta gene segments. Immunogenetics 49(10): 851-9.

Pawelec, G., A. Akbar, et al. (2005). Human immunosenescence: is it infectious? Immunol Rev 205: 257-68.

Penit, C. and F. Vasseur (1988). Sequential events in thymocyte differentiation and thymus regeneration revealed by a combination of bromodeoxyuridine DNA labeling and antimitotic drug treatment. J Immunol 140(10): 3315-23.

Penit, C., F. Vasseur, et al. (1988). In vivo dynamics of CD4-8- thymocytes. Proliferation, renewal and differentiation of different cell subsets studied by DNA biosynthetic labeling and surface antigen detection. Eur J Immunol 18(9): 1343-50.

Petrovsky, N. and V. Brusic (2006). Bioinformatics for study of autoimmunity. Autoimmunity 39(8): 635-43.

Qin, S., M. Wise, et al. (1990). Induction of tolerance in peripheral T cells with monoclonal antibodies. Eur. J. Immunol. 20: 2737-2745.

Rangel, C., J. Angus, et al. (2004). Modeling T-cell activation using gene expression profiling and state-space models. Bioinformatics 20(9): 1361-72. 
Rocha, B., A. A. Freitas, et al. (1983). Population dynamics of T lymphocytes. Renewal rate and expansion in the peripheral lymphoid organs. J Immunol 131(5): 2158-64.

Rocha, B. B. (1987). Population kinetics of precursors of IL 2-producing peripheral T lymphocytes: evidence for short life expectancy, continuous renewal, and postthymic expansion. J Immunol 139(2): 365-72.

Rusthoven, J. J. and R. A. Phillips (1980). Hydroxyurea kills B cell precursors and markedly reduces functional B cell activity in mouse bone marrow. J. Immunol. 124: 781-786.

Scott-Browne, J. P., J. White, et al. (2009). Germline-encoded amino acids in the alphabeta Tcell receptor control thymic selection. Nature 458(7241): 1043-6.

Sereti, I., K. B. Anthony, et al. (2004). IL-2-induced CD4+ T-cell expansion in HIV-infected patients is associated with long-term decreases in T-cell proliferation. Blood 104(3): 775-80.

Souza-e-Silva, H., W. Savino, et al. (2009). A cellular automata-based mathematical model for thymocyte development. PLoS One 4(12): e8233.

Sprent, J., R. E. Anderson, et al. (1974). Radiosensitivity of T and B lymphocytes. II. Effect of irradiation on response of T cells to alloantigens. Eur J Immunol 4(3): 204-10.

Stirk, E. R., C. Molina-Paris, et al. (2008). Stochastic niche structure and diversity maintenance in the T cell repertoire. J Theor Biol 255(2): 237-49.

Taub, D. D., W. J. Murphy, et al. (2010). Rejuvenation of the aging thymus: growth hormonemediated and ghrelin-mediated signaling pathways. Curr Opin Pharmacol 10(4): 408-24.

Thoman, M. L. (1995). The pattern of T lymphocyte differentiation is altered during thymic involution. Mech Ageing Dev 82(2-3): 155-70.

Thomas-Vaslin, V., H. K. Altes, et al. (2008). Comprehensive assessment and mathematical modeling of $\mathrm{T}$ cell population dynamics and homeostasis. J Immunol 180(4): 224050.

Thomas-Vaslin, V., L. Andrade, et al. (1991). Clonal persistence of B lymphocytes in normal mice is determined by variable region-dependent selection. Eur J Immunol 21(9): 2239-46.

Thomas-Vaslin, V., B. Bellier, et al. (2000). Prolonged allograft survival through conditional and specific ablation of alloreactive $\mathrm{T}$ cells expressing a suicide gene [see comments]. Transplantation 69(10): 2154-61.

Thomas-Vaslin, V. and A. A. Freitas (1989). Lymphocyte population kinetics during the development of the immune system. B cell persistence and life-span can be determined by the host environment. Int Immunol 1(3): 237-46.

Thomas-Vaslin, V., A. Six, B. Bellier and D. Klatzmann (in press). Lymphocyte Dynamics and Repertoire, Biological Methods. Encyclopedia of Systems Biology. W. O. Dubitzky W., Kwang-Hyun C., Hiroki Y. (eds), Springer, Heidelberg New York.

Thomas-Vaslin, V., A. Six, B. Bellier and D. Klatzmann (in press). Lymphocytes dynamics repertoires, modeling. Encyclopedia of Systems Biology. W. O. Dubitzky W., Kwang-Hyun C., Hiroki Y. (eds), Springer, Heidelberg New York.

Tsukamoto, H., K. Clise-Dwyer, et al. (2009). Age-associated increase in lifespan of naive CD4 $\mathrm{T}$ cells contributes to T-cell homeostasis but facilitates development of functional defects. Proc Natl Acad Sci U S A 106(43): 18333-8.

Waldmann, H. and S. Cobbold (1998). How do monoclonal antibodies induce tolerance? A role for infectious tolerance? Annu Rev Immunol 16: 619-44. 
Winstead, C. J., C. S. Reilly, et al. (2010). CD4+CD25+Foxp3+ regulatory T cells optimize diversity of the conventional $\mathrm{T}$ cell repertoire during reconstitution from lymphopenia. J Immunol 184(9): 4749-60.

Yehuda, A. B., G. Friedman, et al. (1998). Checkpoints in thymocytopoiesis in aging: expression of the recombination activating genes RAG-1 and RAG-2. Mech Ageing Dev 102(2-3): 239-47.

Yung, R. L. and A. Julius (2008). Epigenetics, aging, and autoimmunity. Autoimmunity 41(4): 329-35.

Zhang, H., K. S. Chua, et al. (2005). Lymphopenia and interleukin-2 therapy alter homeostasis of CD4+CD25+ regulatory T cells. Nat Med 11(11): 1238-43.

Zuniga-Pflucker, J. C. and M. R. van den Brink (2007). Giving T cells a chance to come back. Semin Immunol 19(5): 279. 


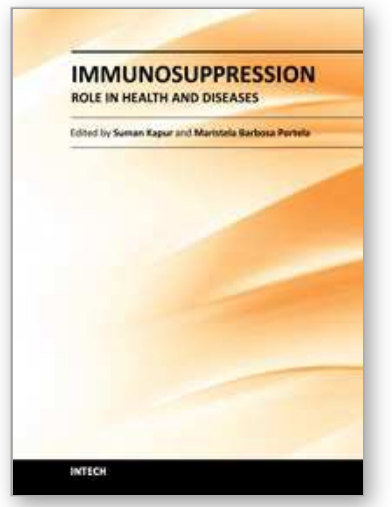

\author{
Immunosuppression - Role in Health and Diseases \\ Edited by Dr. Suman Kapur
}

ISBN 978-953-51-0152-9

Hard cover, 470 pages

Publisher InTech

Published online 24, February, 2012

Published in print edition February, 2012

A need for a book on immunology which primarily focuses on the needs of medical and clinical research students was recognized. This book, "Immunosuppression - Role in Health and Diseases" is relatively short and contains topics relevant to the understanding of human immune system and its role in health and diseases. Immunosuppression involves an act that reduces the activation or efficacy of the immune system. Therapeutic immunosuppression has applications in clinical medicine, ranging from prevention and treatment of organ/bone marrow transplant rejection, management of autoimmune and inflammatory disorders. It brings important developments both in the field of molecular mechanisms involved and active therapeutic approaches employed for immunosuppression in various human disease conditions. There was a need to bring this information together in a single volume, as much of the recent developments are dispersed throughout biomedical literature, largely in specialized journals. This book will serve well the practicing physicians, surgeons and biomedical scientists as it provides an insight into various approaches to immunosuppression and reviews current developments in each area.

\title{
How to reference
}

In order to correctly reference this scholarly work, feel free to copy and paste the following:

Véronique Thomas-Vaslin, Adrien Six, Hang-Phuong Pham, Cira Dansokho, Wahiba Chaara, Bruno Gouritin, Bertrand Bellier and David Klatzmann (2012). Immunodepression and Immunosuppression During Aging, Immunosuppression - Role in Health and Diseases, Dr. Suman Kapur (Ed.), ISBN: 978-953-51-0152-9, InTech, Available from: http://www.intechopen.com/books/immunosuppression-role-in-health-anddiseases/immunodepression-immunosuppression-during-aging-

\section{INTECH}

open science | open minds

InTech Europe

University Campus STeP Ri

Slavka Krautzeka 83/A

51000 Rijeka, Croatia

Phone: +385 (51) 770447

Fax: +385 (51) 686166

www.intechopen.com
InTech China

Unit 405, Office Block, Hotel Equatorial Shanghai

No.65, Yan An Road (West), Shanghai, 200040, China

中国上海市延安西路65号上海国际贵都大饭店办公楼405单元

Phone: +86-21-62489820

Fax: $+86-21-62489821$ 
(C) 2012 The Author(s). Licensee IntechOpen. This is an open access article distributed under the terms of the Creative Commons Attribution 3.0 License, which permits unrestricted use, distribution, and reproduction in any medium, provided the original work is properly cited. 